\title{
CLAUDE LEFORT, AÇÃO E CRÍTICA (O FIO DA MEADA) ${ }^{1}$
}

Sérgio Cardoso ${ }^{2}$

Quando consideramos os primeiros vinte anos de realização do grande projeto de modernização da Universidade brasileira - os anos que vão de 1934 a 1954 - não podemos deixar de nos surpreender, sempre mais uma vez, com o quinhão de sorte com que contou esta empresa: a colaboração de muitos jovens professores estrangeiros, cujo valor excepcional viria a ser comprovado mais tarde por obras de grande significação em seus respectivos campos de investigação.

No caso da Faculdade de Filosofia, Bastide, Braudel, Lévi-Strauss são sempre lembrados. No caso da cadeira de Filosofia, o ciclo dos nossos primeiros 20 anos se fecha em 1954 com um nome que não só honra exponencialmente esta galeria, mas que muito nos beneficiou com seu trabalho e com sua amizade. Pois, a partir daí - destes anos de permanência em São Paulo (1953 e 1954) - sempre voltou uma atenção especial ao Brasil, cultivou vínculos de amizade com os colegas brasileiros, dispôs-se - ele que tinha certa resistência à dispersão das viagens - a vir ao Brasil inúmeras vezes (para cursos, congressos, conferências) e recebeu, com uma afabilidade ímpar um grande número de estudantes brasileiros no CETSAS da EHESS (École des Hautes Études en Sciences Sociales).

Minha geração teve o prazer de ouvi-lo inúmeras vezes em São Paulo. Em 1974 ele dá um belo curso no Departamento de Filosofia sobre o Nascimento da Ideologia no contexto do Humanismo Cívico, quando ouvimos, pela primeira vez, nomes como Salutati, L. Bruni e menções ao trabalho de Hans Baron, Guilbert ou Lauro Martines. Em 1975 ele vem para uma reunião da SBPC em Belo Horizonte. Em 1983 vem duas vezes, uma para conferência em Porto Alegre e na USP, outra para curso nas Ciências Sociais. Em 1988 para conferência no Cebrap, no IEA e no nosso Departamento. Nos anos 90 em diante várias vezes para os cursos promovidos por Adauto Novaes (de quem se tornou grande amigo). Isto para lembrar as ocasiões que me vêm à memória.

Eu sempre quis perguntar-lhe sobre as circunstâncias que o trouxeram ao Brasil no início dos anos 50, mas acabei por não o fazer. Sempre me intrigou o fato deste jovem de 29 anos, já "bem situado" no meio intelectual francês, desejar vir ensinar em São Paulo. Em 1945 ele já publicara no número dois do Les Temps Modernes, com recomendação da

\footnotetext{
${ }^{1}$ Dossiê Claude Lefort: esse texto é parte do dossiê publicado a partir das comunicações realizadas no Colóquio Internacional Claude Lefort: a invenção democrática hoje, realizado na Universidade de São Paulo entre os dias 13 e 16 de outubro de 2015.

2 Professor Livre-Docente do Departamento de Filosofia da Faculdade de Filosofia, Letras e Ciências Humanas da Universidade de São Paulo (FFLCH-USP).
} 
parte de Raymond Aron, sendo também próximo de um dos mentores, então, da revista, Merleau-Ponty; tem um engajamento político importante em grupos de esquerda - de 1943 a 1949 no PCI e depois no grupo Socialismo on Barbárie. Entre 1952 e 1954 polemiza, nas páginas do próprio Les Temps Modernes, com a já grande estrela intelectual da França no pósguerra, J.-P. Sartre.

O que teria trazido a São Paulo esse jovem a quem não faltou, logo em seguida à sua volta à França, um posto na Universidade de Paris, como assistente do prestigiado G. Gurvitch - posto que ocupa por dois anos, deslocando-se depois para uma longa permanência em Caen antes de sua ida para a École? É possível que algum dos seus alunos brasileiros dos anos 50, como o professor José Arthur Gianotti, que se tornou seu amigo, possa satisfazer esta persistente curiosidade. Uma curiosidade significativa (como é talvez também significativo não a termos satisfeito). Mas contento-me, por enquanto, com a ideia de uma grande sorte - podermos contar com a amizade, com a atenção e com o trabalho que esse extraordinário pensador político dedicou ao Brasil, ao nosso Departamento e a tantos de nós em particular. Somos muito agradecidos à sua obra e à sua amizade.

O caminho aberto pelo pensamento militante de Claude Lefort parece-me paradigmático das interrogações e das transformações da esquerda no longo século XX um século que se iniciou inteiramente guiado pelo clarão da ideia de Revolução, de transformação total da ordem do mundo, e terminou com o apagão dessa crença, com o seu quase inteiro esvaziamento. No início, o horizonte do compromisso com o projeto de emancipação humana com um corte radical com o passado da exploração humana imbuído, portanto, da crença em um ponto de ruptura radical entre esse passado e o futuro; no final, o gosto amargo de assistir à hegemonia da ordem liberal erigida em fim da história. No início, tudo aponta para o triunfo da Revolução de 1917; pois, o grande acontecimento, o advento do novo, o futuro, parece descortinar-se na União Soviética: lá teria ocorrido o corte radical com o passado da exploração, iniciando-se a era da emancipação e da igualdade; lá nasceria, pois, o homem novo, manifestando a razão na História. Mesmo a intelectualidade ocidental não comunista, como sabemos, se vê conquistada pela imagem da Revolução. Os intelectuais europeus fazem manifestações públicas de simpatia à URSS; justificam sua política interna e externa; multiplicam seus manifestos anti-guerra e antifacismo e relatam, com entusiasmo, suas viagens à URSS. Tornam-se socialistas, comunistas, ou ao menos, como se dizi então, "compagnons de route".

Porém, logo, como sabemos também, vão, grande parte deles, abandonando essa "route": os processos de Moscou (1936 a 1938), o pacto germano-soviético, depois a Hungria, a Tchecoslováquia, as notícias sobre os campos de concentração etc. Pouco restou no final do século daquelas convicções, do grande horizonte revolucionário sobretudo depois do desmoronamento do sistema soviético. O próprio Lefort observava isso em certa ocasião: "hoje até mesmo a palavra capitalismo, dizia, ameaça desaparecer do 
nosso vocabulário". Não há mais "exploração capitalista": vivemos em sociedades "de mercado". Não há mais exploração, há perdedores do strugle for life. Porém, lembro tudo isso porque foi nesse século desconcertante que Lefort fez um caminho admirável, um caminho que talvez pudéssemos ver como inteiramente polarizado pela exigência de compreender a natureza e a lógica da formação social e do regime soviético; as realidades que polarizam as interrogações do século. Pois, sua própria reflexão sobre a Democracia emerge dessa busca de compreensão da dinâmica da Revolução e do percurso do regime soviético.

Pontuemos rapida e sumariamente esse percurso. Começo pelo adolescente de uma família com sensibilidade de esquerda (entusiasmada em 1936 pelo front populaire de Léon Blum), que, pelos 15 anos, fica transtornado - como ele relatou em várias ocasiões - com o livro de Roger Martin du Gard sobre o caso Dreyfuss e que, em seguida, se apressa em ler outro livro do mesmo autor, Les Thibault, deixando-se arrebatar pelas "aventuras do jovem herói que se torna socialista e pacifista, que luta desesperadamente para mobilizar os trabalhadores contra a guerra de 14 e que encontra a morte ao jogar panfletos de um avião sobre as linhas francesas e alemãs", como lembra em entrevista (L`Anti-Mythes).

Aos 17 anos, em 1941-42 (durante a ocupação), descobre o marxismo no curso de filosofia de Merleau-Ponty e passa a frequentar um grupo trotskista, bem como a ler metodicamente Marx, Lenin, Trotski, sob a orientação de um dirigente do grupo que se torna seu amigo. Mas, o encontro com os trotskistas não é casual como ele próprio relata, em 1975, na bela entrevista dada à L'Anti-Mythe. Antes disso, no Lycée Carnot, MerleauPonty lhe perguntara um dia se ele se interessava pela política e depois o que pensava do Partido Comunista. Espantado com suas respostas, Merleau-Ponty pergunta se ele conhece Trotski e, diante da resposta negativa, lhe diz: "se você o conhecesse, você seria trotskista". Pois, ele, de fato, detesta no PCF o dogmatismo, o monolitismo, o culto da autoridade, a disciplina, o "centralismo democrático". Critica na URSS a militarização da sociedade, a hierarquia burocrática, a desigualdade dos salários e ainda o realismo socialista. Ele encontrara em Marx a crítica da sociedade burguesa em todos os seus aspectos, aspirando, pois, por um marxismo antiautoritário e crítico. Assim, em 1943, agora aos 19 anos, tornase trotskista.

Mas o que é, então, tornar-se trotskista? Ser trotskista é, antes de tudo, compreender a URSS como um Estado socialista degenerado; entretanto, socialista. Por que um Estado socialista? Porque manteria as bases socialistas da produção: a propriedade fora nacionalizada (pois houvera abolição da propriedade privada) e a produção planificada (isto é, socializada). Assim, a Revolução está realizada, mesmo que degenerada ou deformada. De que degeneração se trata? A insidiosa e corrosiva degeneração burocrática. A burocracia parasitária tira proveito da repartição do produto daquela produção socializada. Assim, as relações de produção, são socialistas; mas, a revolução foi traída, 
segundo a formulação tornada canônica por Trotsky. É nesse quadro de interpretação e crítica do regime soviético que se movimenta então o jovem Lefort - ainda que, segundo diz, com muitas outras interrogações e reservas relativas ao determinismo histórico, ao papel de direção dado ao proletariado, à sua "aliança de classe" com o campesinato, e outras tantas. Assim, nos seis anos que permanece no Partido Comunista Internacionalista, de 1943 a 1949, as críticas, logo voltadas ao próprio partido, se avolumam. Trotski, pensa ele, havia fetichizado os conceitos de nacionalização, de coletivização da produção, de planificação, de modo a evitar fazer a crítica das relações de produção estabelecidas pelo regime soviético e de modo a afastar a questão da natureza de classe da burocracia bolchevique, tornada acidente, desvio. Lefort encontra um sólido apoio para as suas críticas com a chegada de Castoriadis da Grécia, pois, este já fazia uma precisa análise das relações de produção na União Soviética. Próximos, eles deixam o PCI, em 1949.

Lefort, Castoriadis e um pequeno grupo constituem, então, o coletivo-revista Socialisme ou Barbarie, sob a ideia fundamental de que a URSS constitui uma nova formação econômico-social, que nada tem a ver com o socialismo. O engano de Trotski, diziam, seria o de confundir a forma jurídica da propriedade dos meios de produção, de fato nacionalizados, com seu conteúdo social e econômico efetivo. Ser proprietário não é apenas ter o direito reconhecido de negociar o que é seu no mercado. É o poder de dispor (gerir - usar) do que é seu. Portanto, se está em questão a propriedade dos meios de produção, a questão deve ser: quem dispõe dos meios de produção? Quem determina o que vai ser produzido, como vai ser produzido, como será a divisão do consumo etc. No caso da URSS, a resposta é claríssima: é a burocracia soviética. Logo, nas relações de produção, a burocracia ocupa o lugar que antes ocupavam os capitalistas. Em consequência, temos um capitalismo de Estado, um capitalismo burocrático. Esse capitalismo de Estado, dizem nossos jovens militantes, nada mais faz que realizar uma tendência histórica do desenvolvimento capitalista. E trata-se aqui de um capitalismo mais perverso, visto que a força de trabalho não tem mais qualquer poder de barganha; não pode fazer greve, não tem voz e vida próprias, sugadas pela burocracia.

Enfim, não basta dizer, como Trotski, que “a propriedade pertence à Nação", que os meios de produção foram nacionalizados. É necessário compreender que grupo, que classe, desempenha o papel da Nação nessas relações de produção. Na URSS, a "Nação" encobre, evidentemente, a dominação da burocracia. Estamos em pleno domínio da ideologia. A Nação é projetada no proletariado; o proletariado, em seu partido; o partido, em seu comitê dirigente; o comitê dirigente, em Stalin, o egocrata. Enfim, só haverá efetivamente propriedade coletivizada, quando os trabalhadores dispuserem eles mesmos das condições e meios da produção, quando forem eles próprios seus gestores, ou seja, quando houver auto-gestão. 
O que seria, então, a verdadeira Revolução? Seria, evidentemente, a abolição da divisão dirigentes/dirigidos. O que seria o verdadeiro Socialismo? Um poder direto dos trabalhadores e não mais do seu "órgão dirigente", o Partido. O Socialismo, portanto, é a gestão da vida social pelos próprios trabalhadores. Ora, temos aí uma bela definição nominal do socialismo! Mas como passar à sua definição real? Quais são as condições de possibilidade dessa auto-gestão generalizada da produção social? Como isso se faz, como é possível? Castoriadis ainda se move, acredita Lefort, no horizonte do determinismo (aquele da "revolução nas coisas", como diz Merleau-Ponty): o desenvolvimento histórico tornaria por si mesmo a Revolução possível. Tudo se passa, assim, como se bastasse suprimir a propriedade e a burocracia para que a boa sociedade pudesse advir. Mas, observemos bem, o coletivo Socialisme on Barbarie tinha uma grande tese - o caráter de classe da burocracia soviética - e uma linha de orientação política - anti-capitalista e anti-burocrática - de que deduzia outras teses relativas a todos os problemas do movimento operário. O grupo se vê, portanto, pensa Lefort, como o depositário e fiador da compreensão do verdadeiro sentido e da direção da Revolução socialista. Eles pensam que os que empreenderam a crítica ao "socialismo real" e compreenderam o sentido da revolução devem se organizar e agir (por "meios próprios") para atingir seus objetivos revolucionários. Desse modo, a maioria do grupo - para grande mal-estar de Lefort - via na revista um instrumento para construir uma organização revolucionária e um programa de ação política. Ouçamos o depoimento de Lefort na entrevista à L'Anti-Mythe: "a experiência do grupo é instrutiva, porque revela certos traços, no meu entender, inevitáveis, de um movimento que se crê o embrião da organização revolucionária. Nenhum de meus antigos camaradas, penso, irá contestar: Socialisme on Barbarie, sem perder a noção de sua extrema fragilidade numérica, definia-se como o núcleo da Direção Revolucionária Mundial. O núcleo, evidentemente, destinado a se transformar a partir do momento em que se aglutinasse em torno dele uma vanguarda operária. Mas, enfim, era evidente que encarnávamos potencialmente essa Direção. Uma Direção, certamente, de um gênero novo, dado que seu programa era a autonomia da classe operária, a luta contra a burocracia. Mas, afinal, uma Direção, um organismo cuja meta era conceber as tarefas do movimento operário e abarcar a totalidade dos problemas colocados pelo advento do socialismo nas condições históricas presentes e, por conseguinte, cuja pretensão primeira era definir os traços do futuro próximo. 'Perspectivas e tarefas revolucionárias, conhece-se bem a fórmula que abre o último capítulo de todos os programas submetidos aos Congressos dos grandes partidos; esta fórmula era, evidentemente, também a nossa"”.

É claro, pois, que a crítica que Lefort fazia do bolchevismo já visava o papel atribuído ao "partido revolucionário", de modo que dentro do grupo seu desconforto foi permanente com esta pretensão de Socialisme ou Barbarie em considerar-se "órgão de partido", "ainda que um partido virtual". Lefort via na revista apenas um órgão de reflexão, 
discussão, informação, enfim, um órgão de crítica e interrogação revolucionárias. Assim, a ruptura, anunciada quase desde o início, torna-se definitiva no momento em que, em 1958, com o golpe de De Gaulle, o grupo "pensa que chegou a hora de efetivamente construir a organização com que sonhava". Lefort dirá mais tarde: "penso que naquele momento eles perderam a noção do real". Nesta ruptura, a crítica de Lefort tem dois alvos nítidos: primeiro, a ideia de uma direção revolucionária autônoma. Se a revolução é o poder do proletariado, esse poder, mesmo na revolução, só pode ser exercido por ele. Uma direção, um partido, que agem "por seus próprios meios", que fixa "seus próprios meios", tenderia a subordinar a luta autônoma da classe à sua própria estratégia e decisões políticas. Não se pode pretender dirigir a ação dos movimentos proletários autônomos, como se o 'partido' fosse o proprietário do universal, o detentor do sentido do movimento revolucionário. $\mathrm{O}$ proletariado é capaz de definir ele próprio sua ação e seus objetivos. Uma organização apenas poderia lhe fornecer meios para se desenvolver: clarificação teórica, informações, ligações. Ele já expressava tal posição em um artigo (“L'experience proletarienne”) de 1952: "é apenas do interior do proletariado que pode ganhar forma o conhecimento de sua história, de sua diferenciação, de suas tarefas presentes. Uma direção viria cristalizar esse processo de auto-conhecimento". Um segundo alvo de Lefort nesta sua ruptura com Socialisme on Barbarie visava ao próprio conceito de auto-gestão. É claro que auto-gestão remete a um elemento da dinâmica democrática: a participação nas decisões no campo de produção, da administração, das escolas, e dos vários aspectos da vida social. Porém, diz Lefort, "concebida como modo de funcionamento da sociedade tomada em seu conjunto, [a ideia de auto-gestão] me parece fantasmagórica e mesmo perigosa. Sob a capa da democracia de massas poderia submeter todas as ações e representações ao denominador comum de uma 'vontade do povo'. E a dinâmica da democracia estaria perdida.”

De imediato, pois, em primeiro lugar, a saída de Lefort de Socialisme ou Barbarie está associada a sua crítica da postulação de uma direção revolucionária, que o grupo, a seu modo, pretende encarnar; mas ele não ignora, então, que a ideia de direção está ligada à própria ideia de revolução. A raiz da ilusão, lembra ele, está na representação - herdada de Marx - de um espaço social realmente dividido e destinado a tornar-se realmente unificado. Ou seja: "a redução da divisão social à divisão de duas classes antagonistas que compõe como que duas sociedades em uma só, de modo que uma delas - a dos explorados poderia destruir a outra e dissolver em si todos os elementos adversos, para tornar-se [então] uma sociedade homogênea": sociedade sem divisão, sociedade inteiramente ordenada, orgânica, inteiramente referida a si mesma, transparente para si mesma. Não está, portanto, em causa, no horizonte de sua crítica, apenas a noção de direção e de partido, mas mais profundamente "a crença em uma 'solução', em uma fórmula geral de organização da sociedade”. É isto que ele denuncia como ilusório. 
Estamos, como se vê, às portas da interrogação lefortiana da Democracia, como o próprio filósofo testemunha: "essas reflexões conduziram-me a reinterrogar a ideia de democracia [...] que eu julgava essencial liberar da representação sugerida pela prática da democracia burguesa, contra a qual Marx e Lenin haviam justificadamente dirigido suas críticas. Problema central para mim: pensar uma sociedade que acolha os efeitos da divisão social e os efeitos da história; que acolha a heterogeneidade do social - problema cujo estudo deveria me levar mais e mais na direção de uma reinterpretação do político no sentido que os clássicos davam a esse termo, [...] aquela que meu trabalho sobre Maquiavel veio alimentar a partir de 1956". A história que se segue é conhecida. Maquiavel, o pensador da divisão social constitutiva, da empresa de socialização dos homens como inseparável do conflito, inscrita na oposição dos desejos de 'grandes' e 'povo', vem, de fato, "alimentar", de modo decisivo, este trajeto extraordinário de reflexão crítica. 